\title{
Measurement and numerical simulation on the heat transfer characteristics of reciprocating flow in microchannels for the application in magnetic refrigeration
}

\author{
Zhihao Chen ${ }^{\mathrm{a}, *}$, Yoshio Utaka ${ }^{\text {a }}$ and Yutaka Tasaki ${ }^{\mathrm{b}}$ \\ a Division of Systems Research, Faculty of Engineering, Yokohama National University, Tokiwadai \\ 79-5, Hodogaya, Yokohama 240-8501, Japan

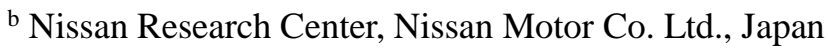

\begin{abstract}
Experimental and numerical studies were conducted on the heat transfer characteristics of reciprocating flow in different types of microchannels for the application in the active magnetic regenerator (AMR) of magnetic refrigeration systems. Experimental measurements were performed for a flat plate type microchannel fabricated using MEMS technique, and with intermittent heating as the boundary condition. The results of the experiments are in good accordance with those of 2-D numerical simulations conducted using the same conditions as the experiments. Therefore, it is considered that the numerical mode is effective for evaluation of the heat transfer for reciprocating flow. Furthermore, numerical simulations on two types of microchannel (flat plate type and staggered mini-plates type) were conducted with alternative heating and cooling conditions which corresponding to the volumetric temperature rise/drop of solid material as a result of magnetocaloric effect. The influence of various factors on the heat transport of reciprocating flow was analyzed. It was found that enhancement of the heat transport could be realized by utilizing the microchannel of staggered mini-plates type, and there is an optimum ratio of amplitude to flow channel length $(\Delta L / L)$ to achieve high efficiency heat transport.
\end{abstract}

Keywords: Magnetic refrigeration, Heat transfer, Efficiency of heat transport, Reciprocating flow, Enhanced heat transfer in microchannels.

\footnotetext{
* Corresponding author. Tel/Fax: +81 453393907.

E-mail: zhchen@ynu.ac.jp
} 


\section{Background and introduction}

Recent research has revealed that heat transfer enhancement could be realized by utilizing reciprocating flow in pipe or parallel channels, especially for high frequency conditions, because a thinner boundary layer is formed with a higher temperature gradient. Numerical studies [1-5] have been conducted on the heat transfer of reciprocating flow in pipes or in 2-D channels in recent years. Ozawa et al. [1] conducted a numerical simulation on the convective heat transfer induced by fluid oscillation and the characteristics of flow field and heat transfer were studied. For the condition of relative higher frequency $(10 \mathrm{~Hz})$, an explicit velocity boundary layer forms near the channel wall, heat transport in the flow direction is mainly through the region near the channel wall, rather than through the bulk liquid region. This indicates that the heat transport is mainly dependent on the thin boundary layer rather than the bulk region for high frequency reciprocating flow. A numerical study on the laminar forced convection of periodically reversing flow in a pipe heated at constant temperature was performed by Zhao and Cheng [2]. They reported that the average heat transfer rate increases with both the kinetic Reynolds number and the dimensionless oscillation amplitude, but decreases with an increase in the length to diameter ratio. Studies on the heat transfer of reciprocating flow in 2-D channels with uniform heat flux and constant temperature boundary conditions were also conducted by a group of researchers [3-5]. Sert and Beskok [3], and Shokouhmand et al. [4] conducted numerical simulations on the heat transfer of reciprocating flows in 2-D channels with uniform heat flux and constant temperature zone on the channel wall. The reciprocating flow Nusselt numbers are comparable to or higher than those for the corresponding unidirectional flow, and at high values of $\alpha$ (Womersley number, which specifies the velocity profile shape), the Richardson annular effect (which results in near-wall velocity overshoots, where the maximum velocity no longer occurs at the symmetry plane) becomes important and heat transfer will be enhanced. The optimum frequency and geometry for maximization of the heat transfer rate was also investigated. Similar calculations were performed by Habibi et al. [5] and the effect of introducing a porous medium on the flow regime of a 2-D channel was investigated. Enhancement of the heat transfer rate could be achieved by introducing a porous material adjacent to the channel wall.

Studies [6-16] on the application of reciprocating flow in some heat transfer devices have also been conducted, especially for the active magnetic regenerator (AMR) of magnetic refrigeration systems. A magnetic refrigeration (Brayton) cycle is comprised of four sequential processes: adiabatic magnetization, heat exchange (heating of fluid), adiabatic demagnetization, and heat exchange (cooling of fluid). In the adiabatic magnetization/demagnetization processes, the temperature of solid material increases/decreases induced by the magnetocaloric effect. The application of reciprocating flow in an AMR is expected to achieve a larger temperature span and higher efficiency (COP: coefficient of performance) of the magnetic refrigeration system by utilizing the combination of 
processes of thermal storage and regeneration. In these studies, boundary conditions corresponding to the temperature variation of a solid material of a flow channel induced by the magnetocaloric effect should be applied, not uniform heat flux or constant temperature boundary conditions. 1-D numerical simulations [6-12] that have involved parametric investigations on the temperature profiles [6,10,11], temperature spans [6,7,9-11], COP [8,9,11,12], and cooling power [7-10,12] have been performed for reciprocating flow in the AMR of magnetic refrigeration systems. In particular, these studies have focused on the effects of changing a few key parameters, such as the fluid mass flow rate, the operating frequency, and the utilization factor (UF), which represents the ratio of the heat capacity of the fluid to the heat capacity of the magnetocaloric material. In these 1-D simulations, convective heat transfer between the solid surface and fluid was simplified by using empirical correlations. 2-D numerical studies have also been conducted for different types of AMRs, such as spherical particle [13] and parallel plate types [14-17]. A 2-D model of a reciprocating flow AMR with a parallel plate was developed by Petersen et al. [14]. The preliminary results indicate that the model has the ability to evaluate the temperature span and it is necessary to use 2-D methods to investigate the reciprocating flow in parallel channels. Nielsen et al. [15] developed a new 2.5D model including parasitic thermal losses and conducted research on the reciprocating flow in parallel channels. It is concluded that the ideal 2D model can be used to explore the performance of a linear reciprocating parallel-plate based AMR, while the $2.5 \mathrm{D}$ model can be used to explore the expected experimental performance in more detail. A comparison of the experimental and numerical results using the 2.5D model was performed by Tura et al. [16]. A 2-D simulation on the performance of a porous media model (spherical particle type) AMR was performed by Li et al. [13] and the cooling capacity was discussed. Experimental study on a Gd-based linear reciprocating AMR was conducted by Trevizoli et al. [17], where the relations of cooling capacity, temperature difference between the sources and UF were observed.

The heat transfer enhancement is essential for improving the performance of the AMR. One of the effective approaches is to utilize the reciprocating flow in microchannel with enhanced heat transfer system. The fundamental knowledge of the heat transfer characteristics of the reciprocating flow in microchannel is essential for the application in AMR. In this study, experimental studies and 2-D numerical simulations were conducted to examine the heat transfer characteristics of reciprocating flow in microchannels. Experiments were performed under intermittent heating conditions on the wall of microchannels. In order to assess the validity of the numerical calculation model, numerical simulations were also conducted with the same conditions as the experiment. Furthermore, in order to simulate the magnetic refrigeration cycle in which both heating and cooling processes exist by the magnetocaloric effect, numerical simulations were also performed on the reciprocating flow in microchannel for the conditions of alternative heating and cooling. Moreover, a special type of microchannel (staggered mini-plates type) was adopted in addition to the normal flat plate type for 
examining the effect of heat transfer enhancement. The heat transfer characteristics are analyzed for the two types of microchannel and the effects of some affecting factors on the heat transport of reciprocating flow are discussed.

Nomenclature

Variables

c heat capacity $(\mathrm{J} / \mathrm{kg} \mathrm{K})$

$f \quad$ frequency $(\mathrm{Hz})$

$h \quad$ thickness of MEMS wafer (mm)

$L \quad$ length of MEMS wafer (mm)

$L^{\prime} \quad$ length of staggered mini-plates (mm)

$\Delta L \quad$ amplitude (mm)

$p \quad$ pressure $(\mathrm{Pa})$

$p_{c} \quad$ set value of pressure $(\mathrm{Pa})$

$\Delta P_{\text {loss }} \quad$ pressure loss $(\mathrm{Pa})$

$Q_{c} \quad$ cold energy transported to the low temperature reservoir (J)

$Q_{m} \quad$ enthalpy drop at the beginning of cooled flow half cycle (J)

$r \quad$ width of microchannel (mm)

$S \quad$ source term of energy equation

$t \quad$ time (s)

$\Delta t \quad$ time step (s)

$T \quad$ temperature (K)

$\Delta T_{\text {rs }} \quad$ temperature difference between high and low temperature reservoir (K)

$\Delta T_{\mathrm{m}} \quad$ temperature change of solid microchannel material (K)

$u \quad$ velocity in $x$ direction $(\mathrm{m} / \mathrm{s})$

$v \quad$ velocity in $y$ direction $(\mathrm{m} / \mathrm{s})$

$v_{x} \quad$ velocity of fluid in $x$ direction $(\mathrm{mm} / \mathrm{s})$

Greek

$\alpha \quad$ thermal diffusivity $\left(\mathrm{m}^{2} / \mathrm{s}\right)$, Womersley number

$v \quad$ kinematic viscosity $\left(\mathrm{m}^{2} / \mathrm{s}\right)$

$\rho \quad$ density $\left(\mathrm{kg} / \mathrm{m}^{3}\right)$

$\eta \quad$ efficiency of heat transport

$\tau_{c} \quad$ cycle of reciprocating flow (s) 


\begin{tabular}{ll}
\multicolumn{2}{l}{ Subscript } \\
l & left side \\
m & middle \\
r & right side \\
H & high temperature side \\
L & low temperature side \\
f & fluid \\
s & solid
\end{tabular}

\section{Experimental apparatus and method}

Experimental studies were performed on reciprocating flow in microchannels using only the intermittent heating condition, because it is difficult to experimentally apply alternative heating and cooling on the wall of microchannels. A schematic view of the experimental system and a cross-section of a test section are shown in Fig. 1. The major components of the experimental system are the microchannel test section, piezoelectric pump and power sources. In the microchannel test section, a microelectromechanical system (MEMS) wafer was arranged on the center line of an acrylic casket. Cr-Ni thermocouples and a nichrome film heater were deposited on the MEMS wafer. Two symmetrical microchannels with the same dimensions are formed by enclosing the MEMS wafer within the acrylic casket. The width of the microchannel is $0.3 \mathrm{~mm}$ and the length is $30 \mathrm{~mm}$. Sinusoidal reciprocating flow was generated in the experiments using a piezoelectric pump and supplied into the microchannel. The other side of the microchannel that is not connected to the pump is opened to the atmosphere. The frequency and amplitude of the sinusoidal reciprocating flow was controlled by changing the frequency and voltage of the input power to the piezoelectric liquid pump. Because it is difficult to experimentally realize alternative heating and cooling on the wall of microchannels, experiments were performed under intermittent heating conditions. The intermittent heating was realized by controlling (on/off) the DC power source for the nichrome film heater deposited on the MEMS wafer, the electrical resistance of which was in the order of $10 \Omega$. The heating time was set as long as $1 / 8$ of a reciprocating flow cycle. The temperature variation on the MEMS wafer was measured using the on-board deposited Cr-Ni thermocouples, and the temperature variation of the inlet/outlet fluid was measured using two T-type sheathed thermocouples arranged in the bulk fluid near the inlet/outlet of the microchannels. All thermocouples were calibrated. The accuracy of the on-board deposited $\mathrm{Cr}-\mathrm{Ni}$ thermocouples was within $0.03 \mathrm{~K}$ and that of the T-type sheathed thermocouples was within $0.1 \mathrm{~K}$.The detailed structure of the MEMS wafer is shown in Fig. 1 (in the circle). The MEMS wafer is a symmetrical laminate structure that is $0.5 \mathrm{~mm}$ thick and 30 $\mathrm{mm}$ long. A silicon substrate is arranged in the center line of the MEMS wafer and several subsequent layers are deposited on the substrate in order; a $0.1 \mu \mathrm{m}$ thick nichrome film layer, a 0.5 
$\mu \mathrm{m}$ thick $\mathrm{SiO}_{2}$ layer, a $200 \mu \mathrm{m}$ thick silicon layer, and a $1.5 \mu \mathrm{m}$ thick $\mathrm{SiO}_{2}$ layer. The $\mathrm{Cr}-\mathrm{Ni}$ thermocouples are deposited in the $\mathrm{SiO}_{2}$ protective coating layer adjacent to the fluid in the microchannel.

\section{Calculation mode}

Numerical simulations for the intermittent heating and the alternative heating and cooling conditions on the microchannel wall were performed. The intermittent heating simulation employed the same conditions (structure of microchannel, physical properties and inlet velocity of fluid) as the experiments, so that the calculation results could be compared with the experimental results to assess the numerical mode.

The alternative heating and cooling condition was employed to simulate the heating and cooling progress induced by the magnetocaloric effect in the AMR of a magnetic refrigeration system. The 2-D domains for the alternative heating and cooling calculation are shown in Fig. 2. For all calculations, it was necessary to calculate only half of the domain by applying the symmetry boundary condition. Two types of microchannels (flat plate as shown in Fig. 2(a) and staggered mini-plates, as shown in Fig. 2(b)) were adopted in the calculation. The latter type was adopted to examine the effect of heat transfer enhancement; therefore, this type of microchannel is also called enhanced heat transfer plate type.

Simulations were conducted using the commercial CFD solver ANSYS Fluent (version 13). Numerical discretization was based on the finite differential method (FDM) and the temporal integration used was first order implicit. The convection term in the momentum and energy equations was implemented following the first order upwind scheme, while the diffusive terms are discretized with central finite-difference scheme. The mesh size is $0.01 \mathrm{~mm}$ in both directions of the 2-D domain.

\subsection{Basic equations}

The basic equations are summarized as follows.

Continuity equation:

$$
\frac{\partial u}{\partial x}+\frac{\partial v}{\partial y}=0
$$

Navier-Stokes equation:

$$
\begin{aligned}
& \frac{D u}{D t}=-\frac{1}{\rho} \frac{\partial p}{\partial x}+v\left(\frac{\partial^{2} u}{\partial x^{2}}+\frac{\partial^{2} u}{\partial y^{2}}\right) \\
& \frac{D v}{D t}=-\frac{1}{\rho} \frac{\partial p}{\partial y}+v\left(\frac{\partial^{2} v}{\partial x^{2}}+\frac{\partial^{2} v}{\partial y^{2}}\right)
\end{aligned}
$$

Energy equation: 


$$
\frac{D T}{D t}=\alpha\left(\frac{\partial^{2} T}{\partial x^{2}}+\frac{\partial^{2} T}{\partial y^{2}}\right)+S
$$

\subsection{Boundary conditions}

For the intermittent heating condition, the boundary conditions of inlet fluid velocity, temperature of inflow/backflow fluid and heat flux on the microchannel wall for heating were applied, and the measured values of them in the experiments were adopted. The velocity of the reciprocating flow was measured from the oscillation of the fluid level in the tube of the outlet (Fig. 3) and applied at one side of the microchannel. The boundary condition on the other side of the microchannel was set as the pressure outlet boundary condition of ANSYS Fluent. Outflow was induced in the first half cycle of reciprocating flow and backflow was induced in the latter half cycle. The temperature of inflow/backflow fluid $\left(T_{\mathrm{L}}\right.$ and $\left.T_{\mathrm{H}}\right)$ was measured at the inlet/outlet of the microchannel at the periodic steady state of temperature variation, the measured values were shown in Table 1 . In the calculations, $T_{\mathrm{L}}$ was used as the inflow temperature in the first half cycle and $T_{\mathrm{H}}$ as the backflow temperature in the latter half cycle, respectively. The heat flux of intermittent heating was calculated based on the input power of heating in the experiments, and applied to the wall corresponding to the location of nichrome film heater on the MEMS wafer. Adiabatic boundary conditions were applied on to the other wall of the microchannel.

For the alternative heating and cooling conditions, a similar method was adopted in the calculation as that for the intermittent heating condition except for the following items. The boundary conditions are summarized in Eq. 5-15. First, the velocity of inlet fluid was calculated based on Eq. 5 instead of using the measured value. Second, it was assumed that two fluid reservoirs with different temperature $\left(T_{\mathrm{L}}\right.$ and $\left.T_{\mathrm{H}}\right)$ are connected to the two sides of microchannel. Since the volume of the two reservoirs is much larger than that of the fluid in the microchannel, the fluid temperature in the two reservoirs could not be influenced by heat transport from the microchannel and was kept constant. For the temperature of inflow fluid temperature $\left(T_{\mathrm{L}}\right)$, a fixed value of $273.15 \mathrm{~K}$ was set, and the backflow temperature was determined based on $T_{\mathrm{L}}$ and the temperature difference between the two fluid reservoirs $\Delta T_{\text {rs }}$, which is one of the given calculation conditions. At last, instead of the heat flux of heating on the microchannel wall in the experiments, temperature variation of magnetocaloric material (solid material of microchannel wall) induced by the magnetocaloric effect was applied. The absolute value of temperature variation of the magnetocaloric material was set as $\Delta T_{\mathrm{m}}(\mathrm{K})$. This temperature variation could be realized by applying a source term to the energy equation. The source term was applied for temperature rise at the beginning of the first and for temperature drop at the beginning of the latter half cycles of reciprocating flow. Besides, the dimensions of the two types of microchannel are summarized in Table 2, and the physical properties of gadolinium $\left(\rho=7990 \mathrm{~kg} / \mathrm{m}^{3}, c=230 \mathrm{~J} / \mathrm{kg} \mathrm{K}, k=10.6 \mathrm{w} / \mathrm{m} \mathrm{K}\right)$ and water $\left(\rho=998.2 \mathrm{~kg} / \mathrm{m}^{3}, c=\right.$ $4182 \mathrm{~J} / \mathrm{kg} \mathrm{K}, k=0.6 \mathrm{w} / \mathrm{m} \mathrm{K}, \mu=1.003 \times 10^{-3} \mathrm{~kg} / \mathrm{m} \mathrm{s}$ ) were used for the numerical simulation. 


$$
\begin{aligned}
& x=-L / 2 \\
& u=\Delta L \pi f \sin (2 \pi f t) \\
& T_{\mathrm{f}}=T_{\mathrm{L}} \quad\left(0<t<\tau_{c} / 2\right), \frac{\partial T_{\mathrm{f}}}{\partial x}=0 \quad\left(\tau_{c} / 2<t<\tau_{c}\right), \frac{\partial T_{\mathrm{s}}}{\partial x}=0 \\
& x=L / 2 \\
& \frac{\partial u}{\partial x}=0, \frac{\partial v}{\partial x}=0 \\
& \frac{\partial T_{\mathrm{f}}}{\partial x}=0 \quad\left(0<t<\tau_{c} / 2\right), \quad T_{\mathrm{f}}=T_{\mathrm{H}} \quad\left(\tau_{c} / 2<t<\tau_{c}\right), \quad \frac{\partial T_{\mathrm{s}}}{\partial x}=0 \\
& y=0 \\
& \frac{\partial u}{\partial y}=0 \quad \frac{\partial v}{\partial y}=0 \\
& \frac{\partial T}{\partial y}=0 \\
& y=(h+r) / 2 \\
& \frac{\partial u}{\partial y}=0 \quad \frac{\partial v}{\partial y}=0 \\
& \frac{\partial T}{\partial y}=0 \\
& t=i \cdot \tau_{c}, i=0,1,2 \cdots \\
& S=c_{\mathrm{s}} \rho \Delta T_{\mathrm{m}} / \Delta t \\
& t=(i+1 / 2) \cdot \tau_{c}, i=0,1,2 \cdots \\
& S=-c_{\mathrm{s}} \rho \Delta T_{\mathrm{m}} / \Delta t
\end{aligned}
$$

4. Comparison of experimental and numerical results

The experimental and numerical results for the intermittent heating condition are shown in Fig. 4(a)(b). The temperature variations at three thermocouple locations (Fig. 1) on the MEMS wafer are plotted for amplitudes $\Delta L=5$ and $15 \mathrm{~mm}$. The three thermocouples are located at $x=5,14,26 \mathrm{~mm}$ from the inlet and the corresponding temperatures are $T_{\mathrm{l}}, T_{\mathrm{m}}$, and $T_{\mathrm{r}}$, respectively. Similar tendencies were observed for different amplitudes at each position. The temperature increases at each position during the initial heating time of each cycle. The temperature then decreases after a heating time of $1 / 8$ cycle, because the heating is stopped and the relatively low temperature water is 
kept flowing into the microchannel. Unlike the temperature variations of $T_{1}$ and $T_{\mathrm{m}}$, the temperature on the right side $\left(T_{\mathrm{r}}\right)$ continues to increase after a small drop. The reason for this is that the water is heated only at the beginning of each reciprocating cycle, so that in the remaining time of the first half cycle, the left part of the MEMS wafer is cooled by the inflowing low temperature water while the right part is heated by the heated flowing water. In the latter half cycle, $T_{1}$ and $T_{\mathrm{m}}$ increase because the backflow of the heated water, $T_{\mathrm{r}}$ decreases because relatively low temperature water flows into the microchannel. These tendencies could be obviously seen for the amplitude $\Delta L=15$ $\mathrm{mm}$. Figure 4 shows that for all the conditions, although some minor deviations exist, the results of experiments and numerical simulation are in good accordance with each other. Therefore, the numerical mode is confirmed to be effective for evaluation of the heat transfer of reciprocating flow.

5. Numerical simulation on the heat transfer of reciprocating flow with alternative heating and cooling

Numerical calculations on the reciprocating flow in the microchannel were also conducted with alternative heating and cooling on the wall. The effects of some factors, such as the temperature difference between the high and low temperature reservoir $\left(\Delta T_{\mathrm{rs}}\right)$, frequency ( $f$ ), and the amplitude $(\Delta L)$ of reciprocating flow are discussed. The calculations were started from the initial conditions at a gauge pressure of $0 \mathrm{~Pa}$, fluid velocity of $0 \mathrm{~m} / \mathrm{s}$ and initial temperature of $T=\left(T_{\mathrm{L}}+T_{\mathrm{H}}\right) / 2$. Iterative calculations were performed until the periodic steady state was achieved. The other parameters for the calculation are summarized in Table 3.

\subsection{Heat transport by reciprocating flow}

In one cycle of reciprocating flow, the wall temperature increases and the heated fluid flows out of the microchannel to the high temperature reservoir side in the first half cycle, after which the wall temperature decreases and the cooled fluid flow reverses to the low temperature reservoir in the latter half cycle. The water flow in the first half cycle is referred to as heating half cycle, and that in the latter half cycle as cooling half cycle. The amount of heat that is transported to the low and high temperature sides is examined here based on the unit inlet/outlet area. The amount of transported heat in the first and latter half cycle could be calculated based on Eqs. 16 and 17, respectively. Accordingly, in the first half cycle, the amount of transported heat is positive if the outflow temperature is higher than $T_{\mathrm{H}}$, otherwise it will be negative. For the latter half cycle, the amount of transported heat is negative if the outflow temperature is lower than $T_{\mathrm{L}}$, otherwise it will be positive. Heat transport per unit area in the first half cycle:

$$
\int\left(T_{x=L / 2}-T_{H}\right) c \rho|u| d r / r
$$

Heat transport per unit area in the latter half cycle: 


$$
\int\left(T_{x=-L / 2}-T_{L}\right) c \rho|u| d r / r
$$

5.1.1 Influence of flow channel geometry (flat plate and staggered mini-plates types)

The variations of heat transport per unit area in one reciprocating flow cycle for each type of flow channel are shown in Fig. 5. The temperature differences between the low and high temperature reservoirs $\left(\Delta T_{\mathrm{rs}}=\left(T_{\mathrm{H}}-T_{\mathrm{L}}\right) / 2\right)$ are taken as a parameter. The other conditions for the numerical simulation are a flow channel length $(L)$ of $30 \mathrm{~mm}$, reciprocating frequency $(f)$ of $1 \mathrm{~Hz}$, and a temperature change of the solid material $\left(\Delta T_{\mathrm{m}}\right)$ of $5 \mathrm{~K}$.

Figure 5 shows that with increase of the temperature difference $\Delta T_{\mathrm{rs}}$, the heat transport per unit area decreases and the negative region in the first half cycle or the positive region in the latter half cycle increases. This indicates an inverse relation between the heat transport and the temperature difference between the low and high temperature reservoirs. In addition, for all five conditions shown in Fig. 5, the heat transport per unit area in a half cycle is higher when using the staggered mini-plates. For the first half cycle, the maximum value is larger and the negative region is smaller. The same tendency could also be observed in the latter half cycle. It is thus conceivable that heat transfer for reciprocating flow in a microchannel is enhanced by using the staggered mini-plates.

\subsubsection{Influence of reciprocating flow amplitude $(\Delta L)$ and length of flow channel $(L)$}

The heat transport per unit area was calculated by taking the reciprocating flow amplitude $(\Delta L)$ and flow channel length $(L)$ as parameters (with other conditions of $f=1 \mathrm{~Hz}, \Delta T_{\mathrm{m}}=5 \mathrm{~K}$ and $\Delta T_{\mathrm{rs}}=40$ $\mathrm{K})$ and the results are summarized in Fig. 6. Because the absolute value of heat transport is symmetric between the first and latter half cycle, only the calculation results for the heating half cycle are analyzed here. For the same $L$, the heat transport per unit area varies significantly with $\Delta L$. The maximum value of heat transport per unit area increases with the increase of $\Delta L$, but the negative region and its absolute value also increases. Therefore, it is conceivable that integration of the heat transport per unit area in one half cycle has an optimum value with the variation of $\Delta L$. Furthermore, for the same $\Delta L$, the heat transport per unit area increases with the increase of $L$. This is because the longer microchannel has a larger solid material mass of microchannel wall, so that more heat is generated or drawn off with the same temperature change $\Delta T_{\mathrm{m}}$, of the solid material.

\subsection{Efficiency of heat transport}

The efficiency of heat transport is discussed here to evaluate the heat transport ability of reciprocating flow in microchannels. The efficiency of heat transport $\eta$, is defined by Eq. 18:

$$
\eta=\frac{Q_{c}}{Q_{m}}
$$


where $Q_{c}$ : cold energy transported to the low temperature reservoir, and

$Q_{m}$ : enthalpy drop at the beginning of the cooling half cycle.

5.2.1 Relationship between efficiency of heat transport $\eta$ and $\Delta T_{\mathrm{rs}} / \Delta T_{\mathrm{m}}$

The relationship between the efficiency of heat transport and the ratio of the temperature difference of the high and low temperature reservoirs to the temperature change of the solid material $\left(\Delta T_{\mathrm{rs}} / \Delta T_{\mathrm{m}}\right)$ is shown in Fig. 7. The efficiency of heat transport decreases with increasing $\Delta T_{\mathrm{rs}} / \Delta T_{\mathrm{m}}$. Because the value of $\Delta T_{\mathrm{m}}$ is not changed in the calculations, this tendency is similar to the discussion in section 5.1(a), in that the heat transport decreases with the increase of $\Delta T_{\text {rs }}$. In addition, relatively high efficiency heat transport could be achieved with the staggered mini-plates; the convective heat transfer between fluid and the microchannel wall is enhanced.

5.2.2 Relationship between the efficiency of heat transport $(\eta)$ and ratio of amplitude to channel length $(\Delta L / L)$

The influence of the reciprocating flow amplitude $(\Delta L)$ and the length of the flow channel $(L)$ are discussed here. Only the results for the microchannel of staggered mini-plates type are summarized here. The relationship between $\eta$ and $\Delta L / L$ are shown in Fig. 8 for conditions of $f=1 \mathrm{~Hz}, \Delta T_{\mathrm{m}}=5 \mathrm{~K}$, and $\Delta T_{\mathrm{rs}}=40 \mathrm{~K}$, with $L$ as a parameter. For each length of flow channel, a similar tendency of heat transport efficiency is observed. The efficiency of heat transport varies with $\Delta L / L$ and has a maximum value that corresponds to a certain range of $\Delta L / L$. Therefore, there is an optimum ratio of $\Delta L / L$ to achieve high efficiency heat transport. For the calculation conditions used in this study, the optimum ratio is in the range of 0.15-0.25. A relatively higher efficiency of heat transport could be achieved when a longer flow channel is adopted, because more heat can be generated with a longer channel, as discussed in section 5.1.2.

\subsection{Pressure loss}

The results above indicate that a relatively high efficiency of heat transfer could be achieved, especially for the staggered mini-plates. However, it is considerable that the pressure loss will be increased when using a microchannel, especially for the staggered mini-plates type.

The efficiency of heat transport with consideration of the pressure loss was calculated and compared to the former results without consideration of the pressure loss, as shown in Fig. 9. The energy consumption caused by pressure loss is calculated and added to the denominator $\left(Q_{\mathrm{m}}\right)$ of Eq. 18. For both types of microchannel adopted in this study, the heat transfer efficiency becomes lower with consideration of pressure loss. However, there is a larger drop of efficiency for the staggered mini-plates type microchannel. For the range of low $\Delta T_{\mathrm{rs}} / \Delta T_{\mathrm{m}}$, the efficiency of heat transport for the staggered mini-plates type is smaller than that of the flat plate type, in contrast to that when the influence of pressure loss is not considered. Therefore, the influence of pressure loss can not be 
ignored in practical applications.

\section{Conclusions}

Experimental and numerical studies were conducted on the heat transfer of reciprocating flow for different types of microchannels with intermittent heating or alternative heating and cooling on the channel wall. The main conclusions are summarized as follows.

(1) Experimental investigations were conducted with intermittent heating condition and numerical simulations were performed with the same conditions. The experimental and numerical simulation results were in good accordance.

(2) Simulations were conducted under conditions of alternative heating and cooling. The heat transport per unit area varied significantly with change of the reciprocating flow amplitude $(\Delta L)$. An optimum ratio of amplitude to flow channel length $(\Delta L / L)$ was determined for achieving higher efficiency heat transport.

(3) By utilizing the microchannel of staggered mini-plates type, notable heat transport enhancement could be realized in comparison with the flat plate type.

\section{References}

[1] M. Ozawa, T. Takifuji and A. Kawamoto, Convective heat transfer induced by fluid oscillation, Trans. JSME (B), Vol. 62, No. 598, 1996.

[2] T. Zhao and P. Cheng, A numerical solution of laminar forced convection in a heated pipe subjected to a reciprocating flow, Int. J. Heat Mass Transfer, Vol. 38, No. 16, pp. 3011-3022, 1995.

[3] C. Sert and A. Beskok, Numerical simulation of reciprocating flow forced convection in two-dimensional channels, J. Heat Transfer, Vol. 125, pp. 403-412, 2003.

[4] H. Shokouhmand, A. Mosahebi and B. Karami, Numerical simulation and optimization of heat transfer in reciprocating flows in two dimensional channels, Proceedings of the World Congress on Engineering, Vol. II, 2008.

[5] K. Habibi, A. Mosahebi and H. Shokouhmand, Heat transfer characteristics of reciprocating flows in channels partially filled with porous medium, Trans. Porous Med., Vol. 89, pp. 139-153, 2011.

[6] T. Kawanami and K. Sakurai, Cooling performance of room-temperature magnetic refrigerator with active magnetic regenerator (Numerical analysis on cooling performance), Trans. JSME (B), Vol. 73, No. 735, pp. 2323-2330, 2007.

[7] M. Risser, C. Vasile, T. Engel, B. Keith and C. Muller, Numerical simulation of magnetocaloric system behavior for an industrial application, Int. J. Refrig., Vol. 33, pp. 973-981, 2010.

[8] C. Aprea and A. Maiorino, A flexible numerical mode to study an active magnetic refrigerator for 
near room temperature applications, Appl. Energy, Vol. 87, pp. 2690-2698, 2010.

[9] G. Tagliafico, F. Scarpa and F. Canepa, A dynamic 1-D model for a reciprocating active magnetic regenerator; influence of the main working parameters, Int. J. Refrig., Vol. 33, pp. 286-293, 2010.

[10] J. Roudaut, A. Kedous-Lebouc, J.-P. Yonnet and C. Muller, Numerical analysis of an active magnetic regenerator, Int. J. Refrig., Vol. 34, pp.1797-1804, 2011.

[11] D. Vuarnoz, T. Kawanami, Numerical analysis of a reciprocating active magnetic regenerator made of gadolinium wires, Appl. Therm. Eng., Vol. 37, pp. 388-395, 2012.

[12] U. Plaznik, J. Tusek, A. Kitanovski and A. Poredos,_Numerical and experimental analyses of different magnetic thermodynamic cycles with an active magnetic regenerator, Appl. Therm. Eng., Vol. 59, pp. 52-59, 2013.[13] J. Li, T. Numazawa, H. Nakagome and K. Matsumoto, Numerical modeling on a reciprocating active magnetic regenerator refrigeration in room temperature, Cryogenics, Vol. 51, pp. 347-352, 2011.

[14] T. F. Petersen, N. Pryds, A. Smith, J. Hattel, H. Schmidt, H. Knudsen, Two-dimensional mathematical model of reciprocating room-temperature active magnetic regenerator, Int. J. Refrig., Vol. 31, pp. 432-443, 2008.

[15] K. K. Nielsen, C. R. H. Bahl, A. Smith, R. Bjørkb, N. Prydsb and J. Hattela, Detailed numerical modeling of a linear parallel-plate active magnetic regenerator, Int. J. Refrig., Vol. 32, pp. 1478-1486, 2009.

[16] A. Tura, K. K. Nielsen and A. Rowe, Experimental and modeling results of a parallel plate based active magnetic regenerator, Int. J. Refrig., Vol. 35, pp. 1518-1527, 2012.

[17] P. V. Trevizoli, J. R. Barbosa Jr. and R. T. S. Ferreira, Experimental evaluation of a Gd-based linear reciprocating active magnetic regenerator test apparatus, Int. J. Refrig., Vol. 34, pp. 1518-1526, 2011. 


\section{Table Captions}

Table 1. Fluid temperature near the inlet/outlet of the microchannel.

Table 2. Dimensions of microchannel.

Table 3. Calculation conditions.

\section{Figure Captions}

Fig. 1. Schematic view of the experimental system.

Fig. 2. 2-D domains for calculation of the alternative heating and cooling condition.

Fig. 3. Velocity of inlet fluid.

Fig. 4. Comparison of temperature variations for the heating surface of the microchannel.

Fig. 5. Variations of heat transport per unit area for various $\Delta T_{\mathrm{rs}}$.

Fig. 6. Heat transport per unit area (influence of $\Delta L$ and $L$ ).

Fig. 7. Efficiency of heat transport (influence of $\Delta T_{\mathrm{rs}} / \Delta T_{\mathrm{m}}$ ).

Fig. 8. Efficiency of heat transport (influence of $\Delta L / L$ ).

Fig. 9. Efficiency of heat transport with and without consideration of the pressure loss. 
Table 1 Fluid temperature near the inlet/outlet of the microchannel.

\begin{tabular}{cccc}
\hline Amplitude $\Delta L(\mathrm{~mm})$ & Frequency $f(\mathrm{~Hz})$ & $T_{\mathrm{H}}\left({ }^{\circ} \mathrm{C}\right)$ & $T_{\mathrm{L}}\left({ }^{\circ} \mathrm{C}\right)$ \\
\hline 5 & 1 & 33.6 & 31.6 \\
15 & 1 & 33.1 & 32.7 \\
\hline
\end{tabular}

Table 2 Dimensions of microchannel.

\begin{tabular}{ll}
\hline Wall thickness of microchannel $h(\mathrm{~mm})$ & 0.2 \\
\hline Width of flow channel $r(\mathrm{~mm})$ & 0.4 \\
\hline Length of flow channel $L(\mathrm{~mm})$ & 30,60 \\
\hline
\end{tabular}

Table 3 Calculation conditions

\begin{tabular}{|c|c|c|c|c|c|c|c|c|}
\hline & $\begin{array}{c}L \\
\mathrm{~mm}\end{array}$ & $\begin{array}{r}L^{\prime} \\
\mathrm{mm}\end{array}$ & $r \mathrm{~mm}$ & $\begin{array}{c}h \\
\mathrm{~mm}\end{array}$ & $\begin{array}{c}f \\
\mathrm{~Hz}\end{array}$ & $\begin{array}{c}\Delta L \\
\mathrm{~mm}\end{array}$ & $\begin{array}{c}\Delta T_{\mathrm{rs}} \\
\mathrm{K}\end{array}$ & $\begin{array}{c}\Delta T_{\mathrm{m}} \\
\mathrm{K}\end{array}$ \\
\hline Flat plate & 30 & & 0.4 & 0.2 & 1 & 5 & $\begin{array}{l}5,10,20 \\
40,50\end{array}$ & 5 \\
\hline $\begin{array}{l}\text { Enhanced } \\
\text { heat } \\
\text { transfer } \\
\text { plate }\end{array}$ & $\begin{array}{l}30 \\
60\end{array}$ & 1 & 0.4 & 0.2 & 1 & $\begin{array}{l}2.5,5.0,7.5 \\
10,15,20 \\
5,10,15,20 \\
30,40\end{array}$ & $\begin{array}{l}5,10,20 \\
40,50\end{array}$ & 5 \\
\hline
\end{tabular}




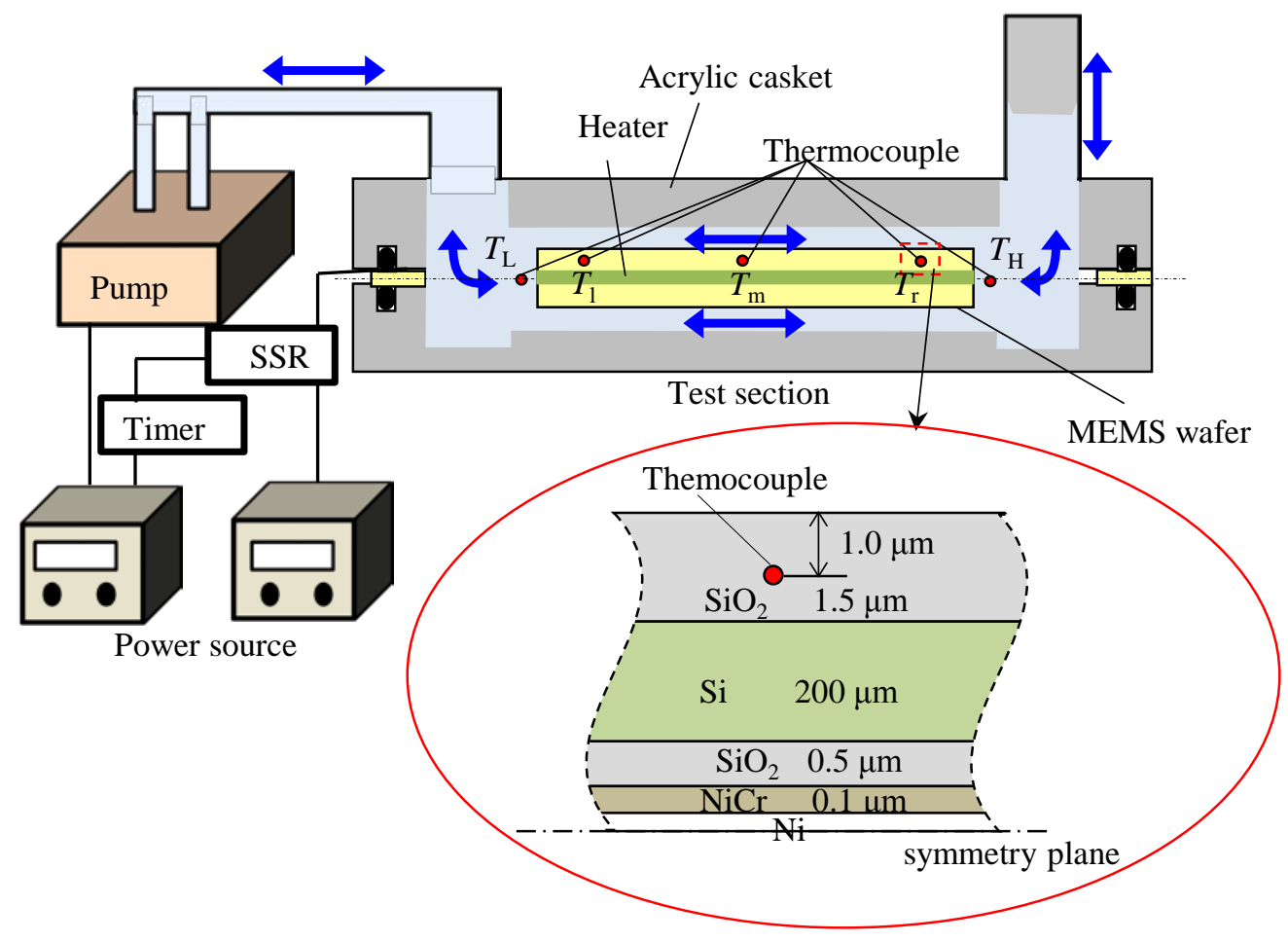

Fig. 1. Schematic view of the experimental system. 
(a)

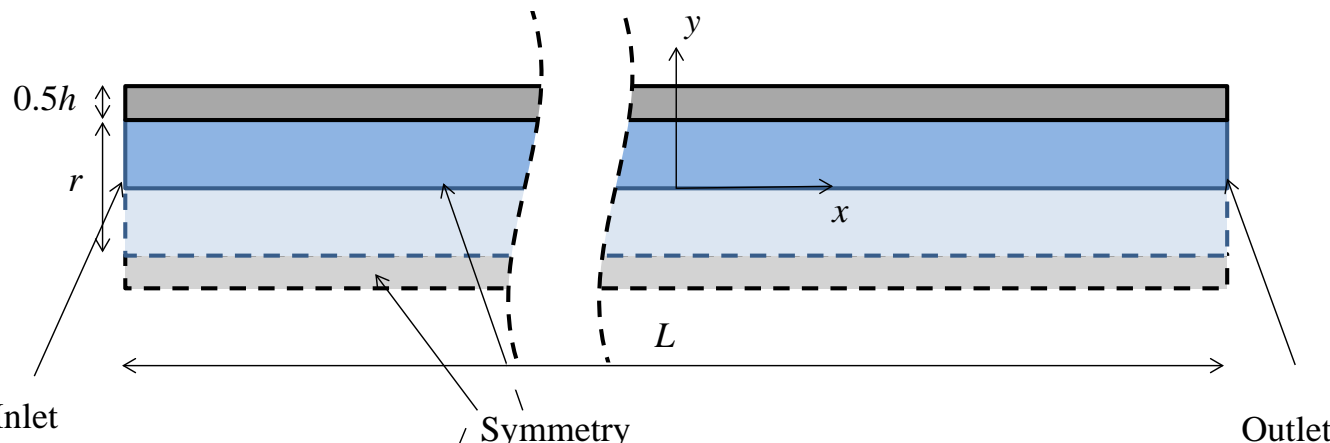

(b)

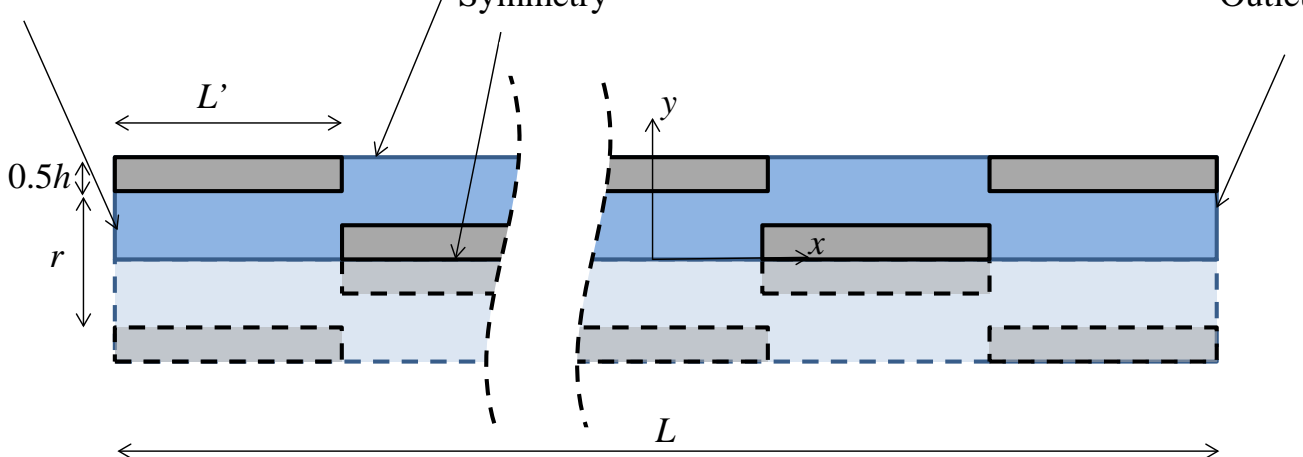

Fig. 2. 2-D domains for calculation of the alternative heating and cooling condition. 


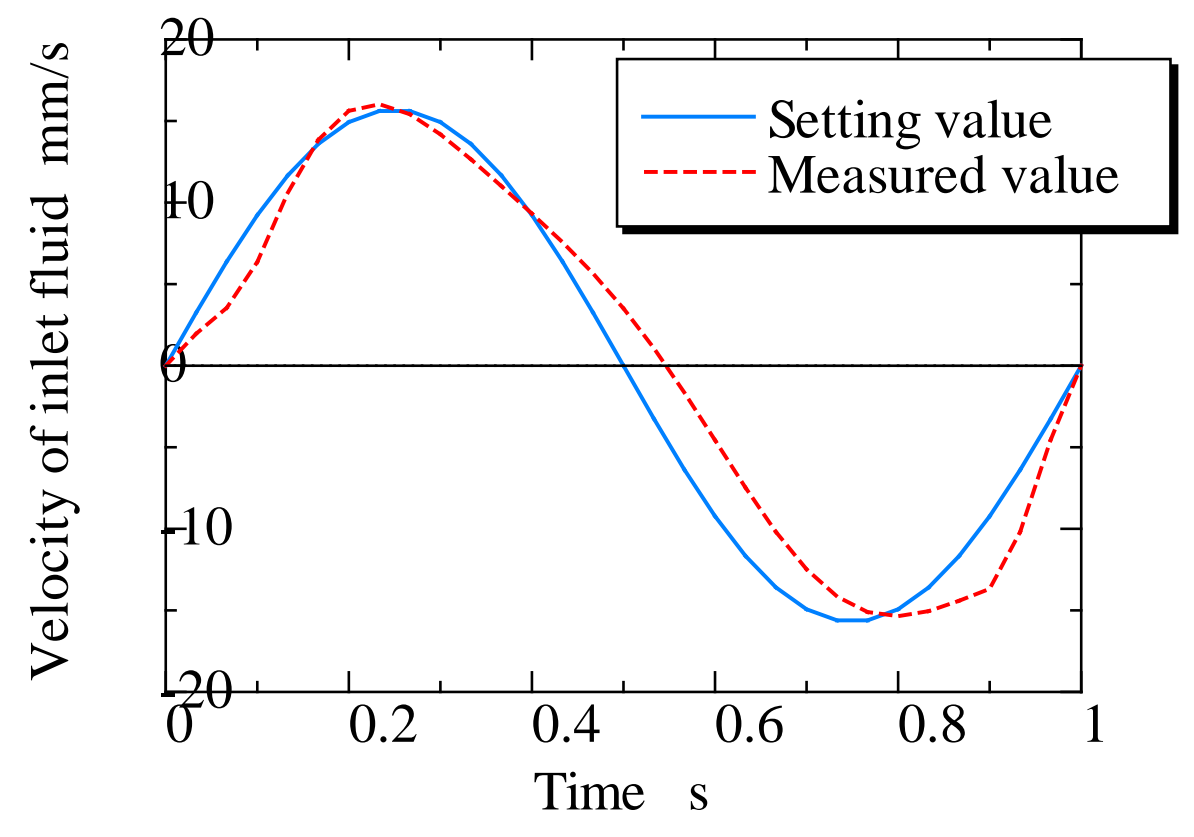

Fig. 3. Velocity of inlet fluid. 


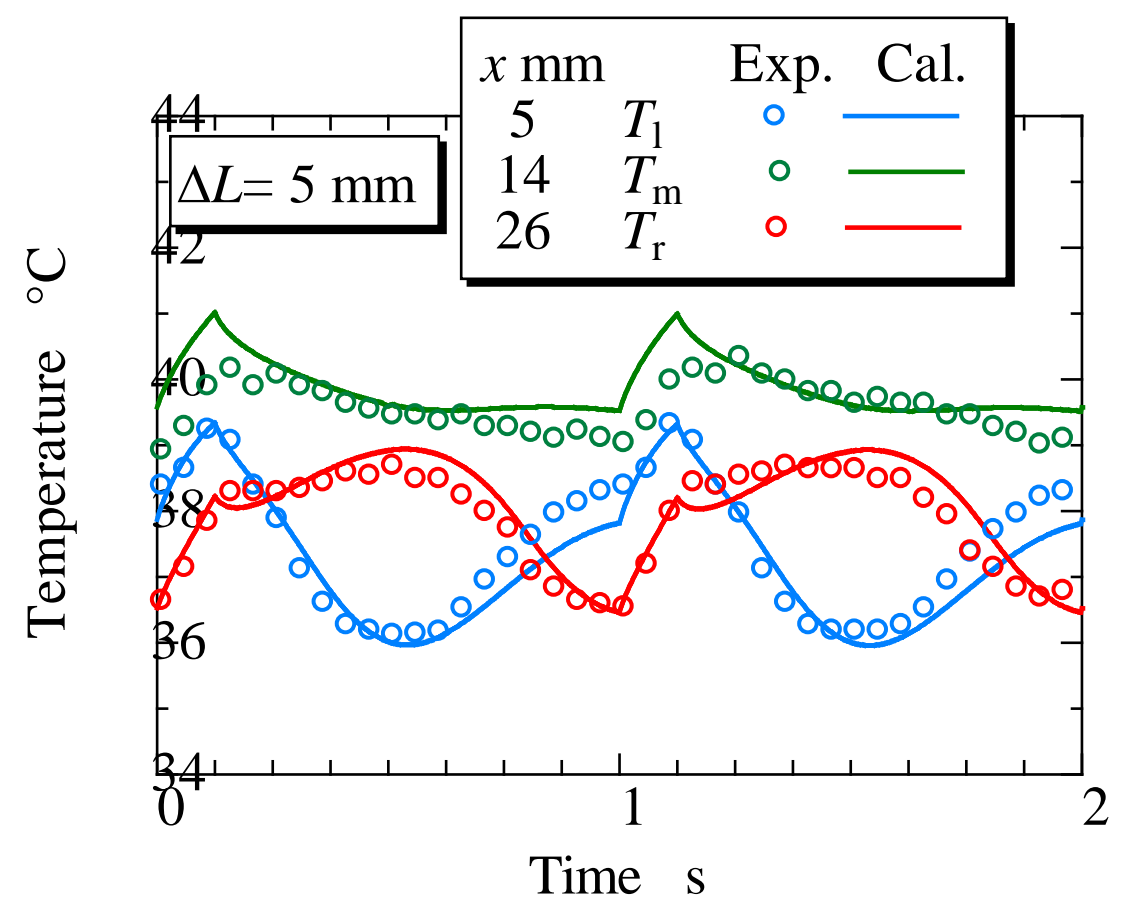

(a) $\Delta L=5 \mathrm{~mm}, f=1 \mathrm{~Hz}$

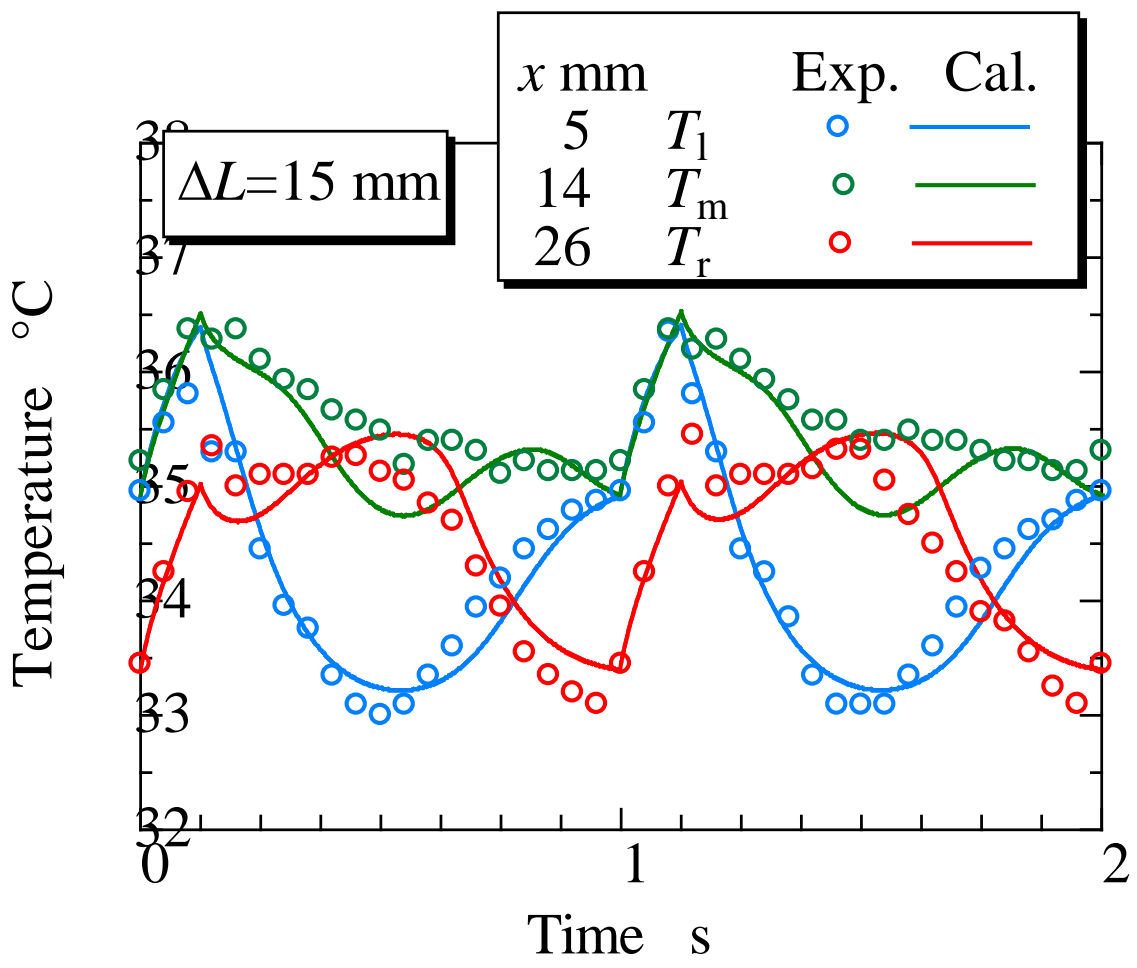

(b) $\Delta L=15 \mathrm{~mm}, f=1 \mathrm{~Hz}$

Fig. 4. Comparison of temperature variations for the heating surface of the microchannel. 


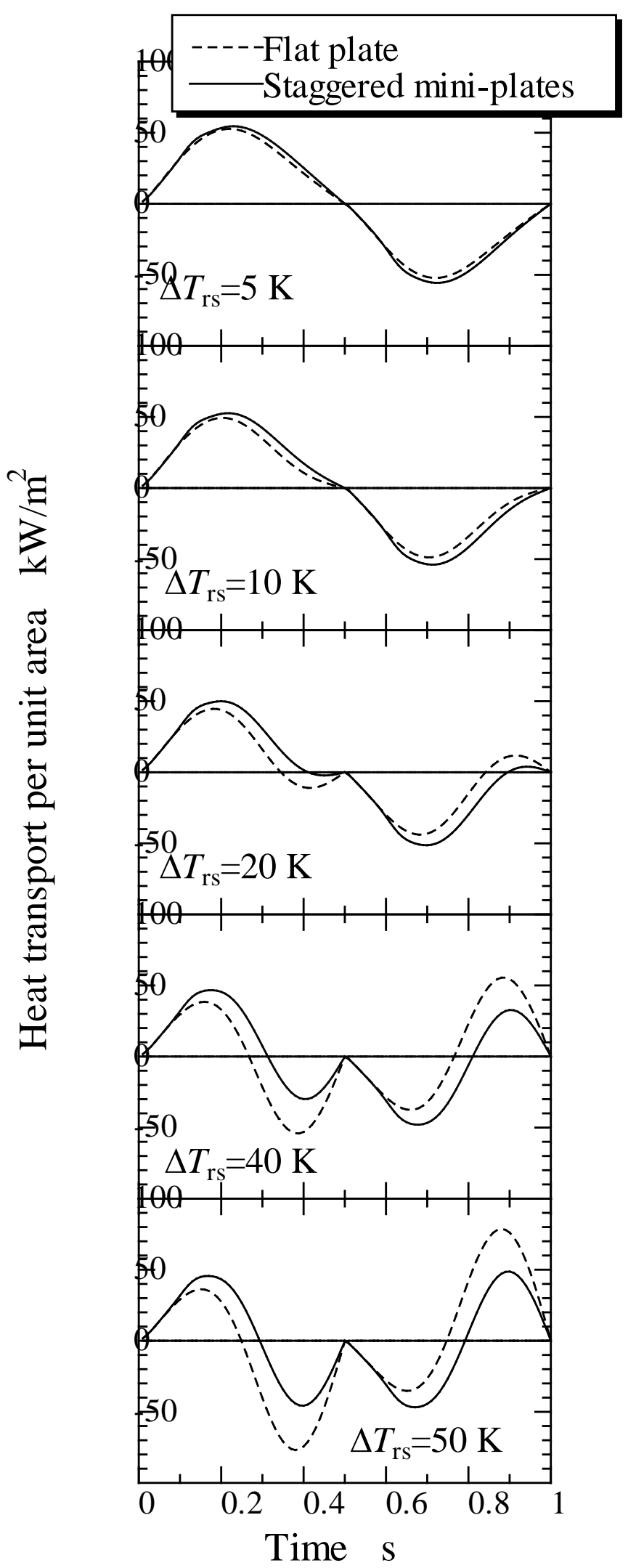

Fig. 5. Variations of heat transport per unit area for various $\Delta T_{\mathrm{rs}}$. 


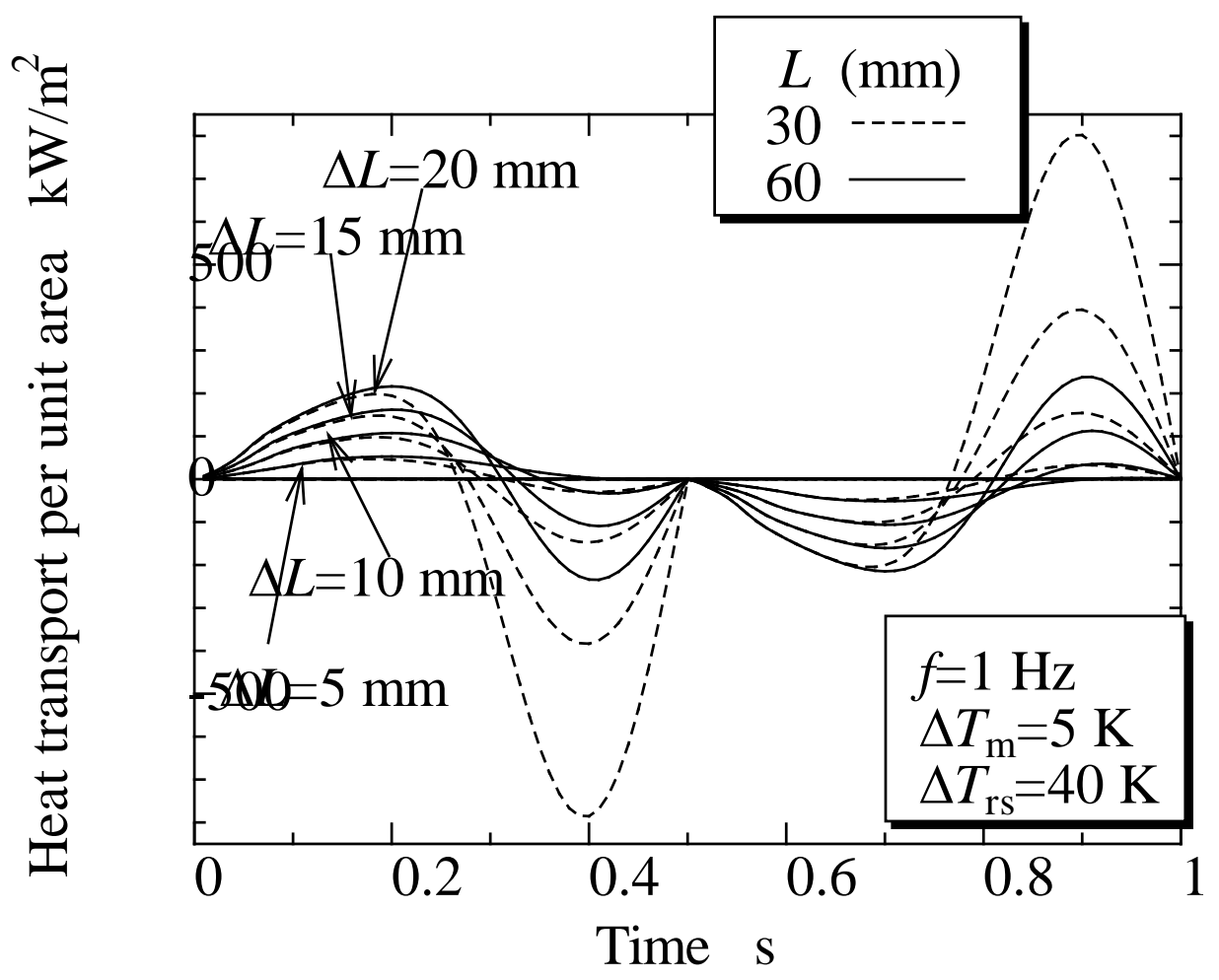

Fig. 6. Heat transport per unit area (influence of $\Delta L$ and $L$ ). 


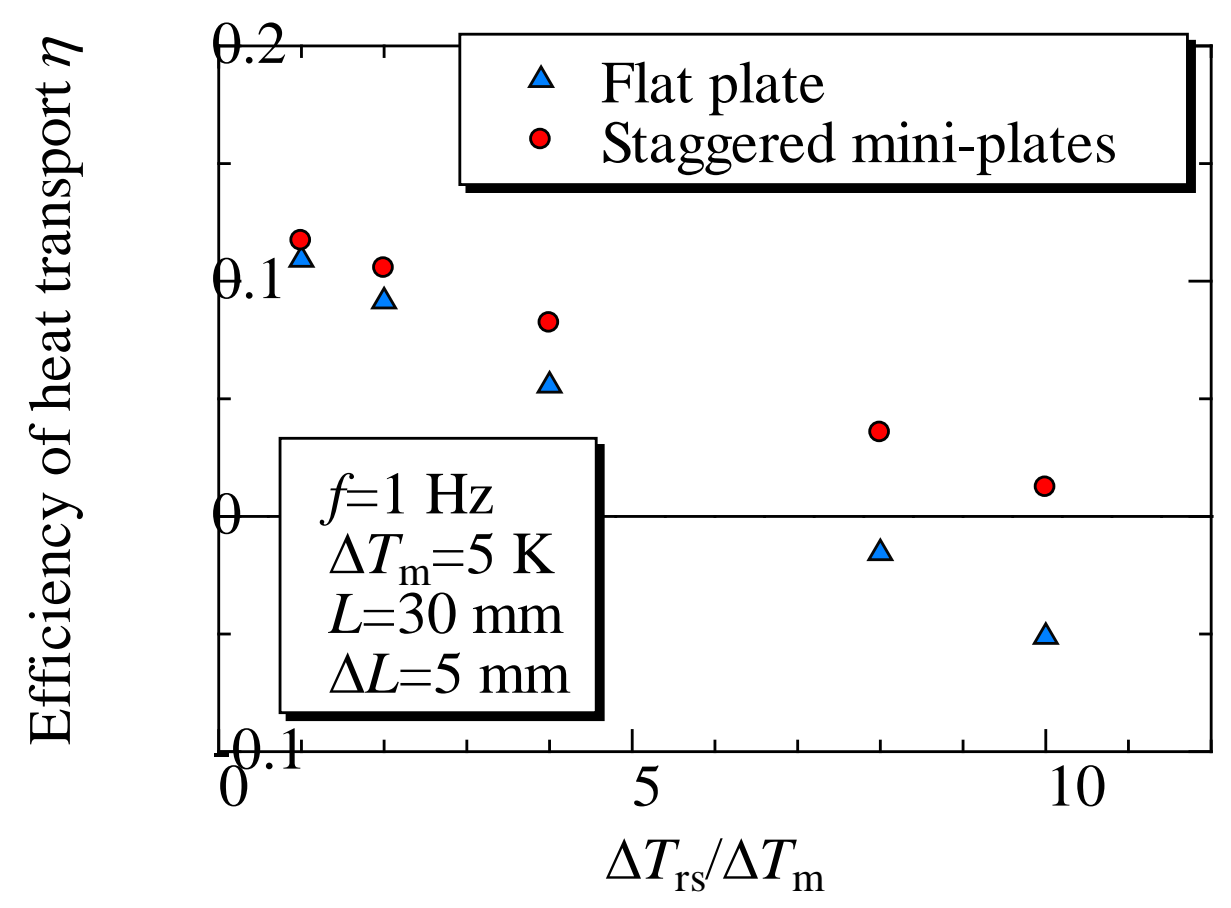

Fig. 7. Efficiency of heat transport (influence of $\Delta T_{\mathrm{rs}} / \Delta T_{\mathrm{m}}$ ). 


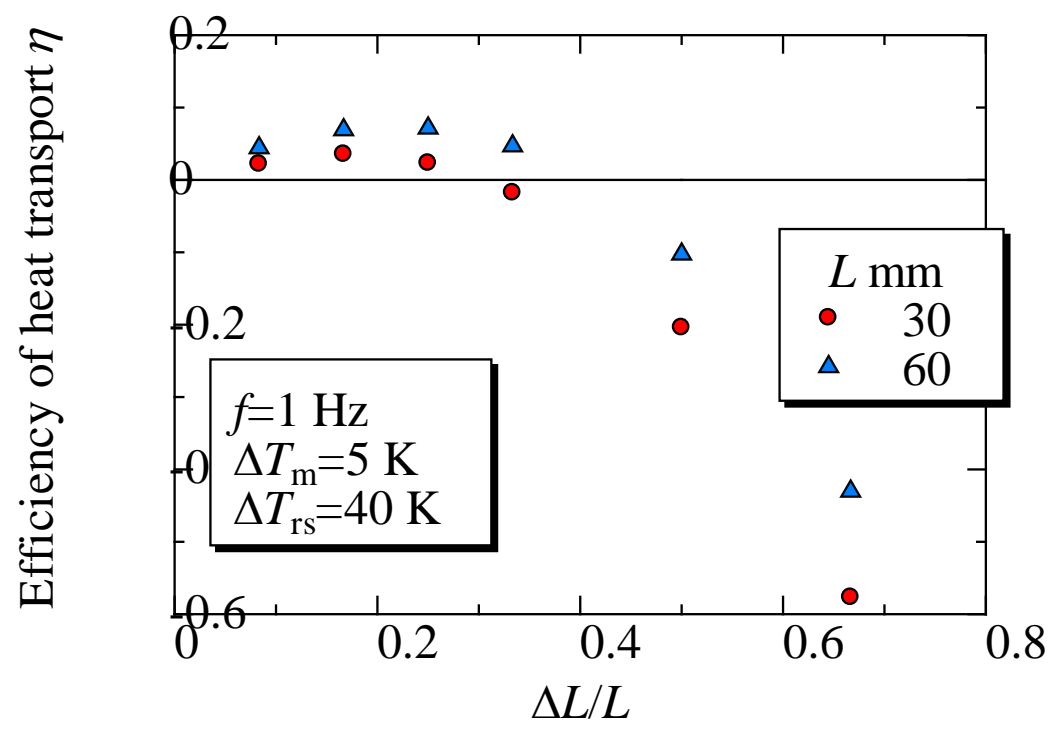

Fig. 8. Efficiency of heat transport (influence of $\Delta L / L$ ). 


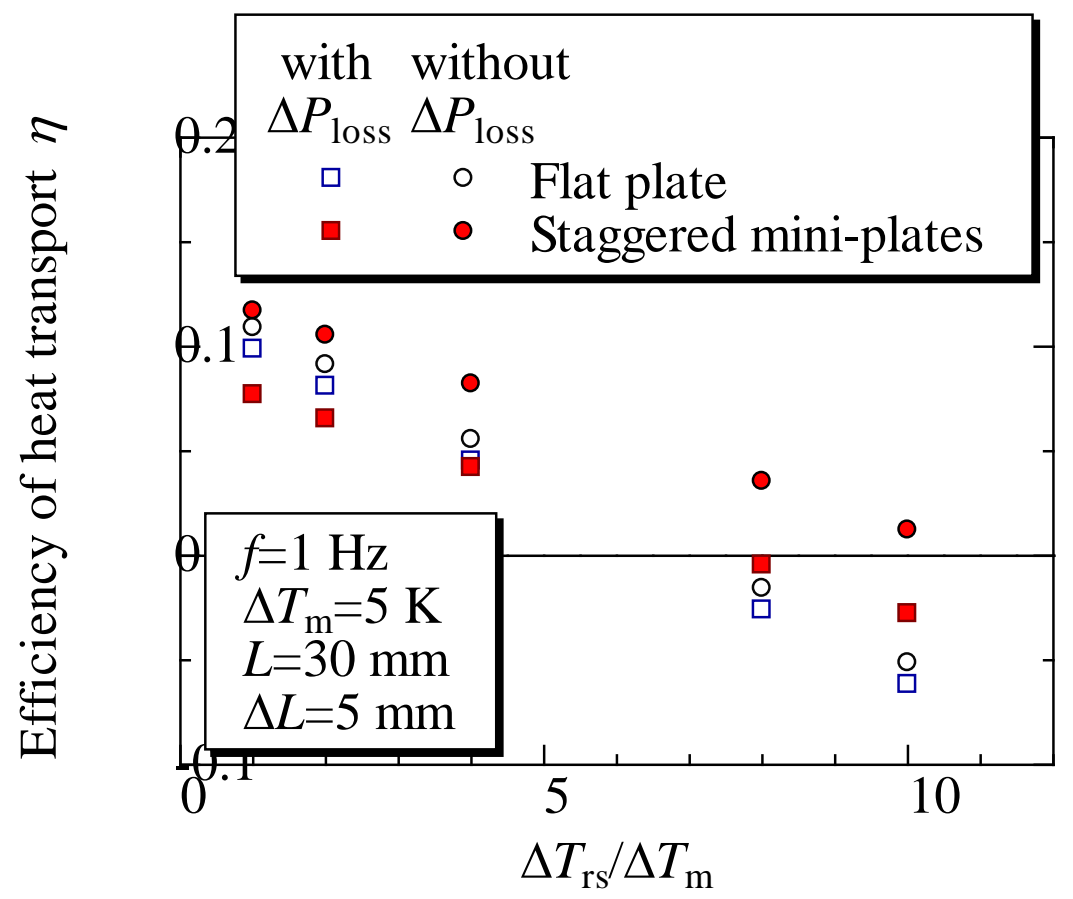

Fig. 9. Efficiency of heat transport with and without consideration of the pressure loss. 